\title{
A Study of 120 Umbilical Cord Whole Blood Transfusions in 77 Patients with Different Clinical Conditions
}

\author{
Dharmesh Chandra Sharma ${ }^{1 *}$, Nidhi Agrawal, ${ }^{2}$ Jyoti Bindal, ${ }^{3}$ \\ Poonam Woike, ${ }^{4}$ A. S. Tomar, ${ }^{5}$ Anita Arya ${ }^{6}$ \\ ${ }^{I}$ Associate Blood Transfusion Officer (ABTO), Incharge Component \& Aphaeresis Unit, \\ Blood Bank, G. R. Medical College, Gwalior. INDIA. \\ ${ }^{2}$ Resident Department of Obstetrics \& Gynecology, G. R. Medical College, Gwalior. \\ ${ }^{3}$ Professor and HOD Department of Obstetrics \& Gynecology G. R. Medical College, Gwalior. \\ ${ }^{4}$ Resident Department of Pathology, G. R. Medical College, Gwalior. \\ ${ }^{5}$ Medical Officer Blood Bank, G. R. Medical College, Gwalior. \\ ${ }^{6}$ Medical Officer Blood Bank, G. R. Medical College, Gwalior.
}

*Corresponding Author, Email id-sharmadrdharmesh@gmail.com

\begin{abstract}
Background-After birth, placenta is normally discarded and has $80 \mathrm{ml}$ to $150 \mathrm{ml}$ whole human blood. Placental cord blood, because of its rich mix of fetal and adult hemoglobin, plasma with higher concentration of cytokines and growth factors along with high platelet and leukocyte count has the potential to be a safe alternative to adult human blood and is useful in transfusion dependent patients as well as in degenerative, autoimmune and geriatric conditions. It could be saved, stored and utilized in the goodness of the patients.

Aims and Objectives Present study is aimed to establish the fact that Umbilical cord blood is safe for transfusion and a true alternative to adult human blood, furthermore its usefulness in different clinical conditions.

Materials and Methods The present study was carried out from $1^{\text {st }}$ February 2015 to $31^{\text {st }}$ August 2016 at a tertiary care centre. A total number of 150 umbilical cord blood units were collected and 120 fit units were transfused to 77 pre-registered patients. Follow up of the patients for three months was done to observe the outcome of transfusions. All data was collected, compiled and compared statistically by frequency distribution and percentage proportion.

Results - In the study, mean blood volume in ml/unit was 80.75 \pm 13.06 SD. Average age of patients in years was 26.19 $\pm 20.5 S D$. Out of 77 Patients, males were 46(59\%) and Females were 31(41\%). ABO group distribution of the patients was A:20, B:34, O:16 and AB:7. 120 Cord blood units transfused to following patients;Thallassemia32, Vitiligo30, hematopoietic malignancies15, Anemia14, Aplastic anemia12, geriatric Patients 09, sickle cell anemia 04, retinitis pigmentosa 02 and Idiopathic Thrombocytopenia 02. In transfusion dependent patients, hemoglobin was increased by 0.5-1 gm/dl, RBCs volume reduced by 10-20\% and interval between two transfusions increased by $10 \pm 2$ days. Re-pigmentation in Vitiligo, Improvement in vision field in retinitis pigmentosa, control of blood sugar in diabetes, and general improvement in geriatric patients was observed. Adverse event was reported in 02 (1.6\%) transfusions.

Conclusion- From our observations, we concluded that umbilical cord whole blood is a genuine alternative of adult human blood. It is helpful in correction of anemia in transfusion dependent patients, useful in neonatal transfusion and a hope for geriatric, autoimmune and degenerative disorders.
\end{abstract}

Keywords: Umbilical cord whole blood, Adult human blood, Transfusion, stem cell, cytokines and growth factor

\section{Introduction}

Blood Transfusion Service (BTS) is an essential part of modern health care system without which medical care is impossible [1]. Till date, there is no substitute of human blood [2]. Even after all efforts for voluntary blood donation and blood component therapy, there is substantial gap between demand and supply, especially in under developed and developing countries like India [3,4]. In India, the ratio of usage of blood components to whole blood is $15: 85$, while globally it is $90: 10$, further widened the gap of demand and supply of blood components [5]. As for as artificial substitutes of blood is concern, no truly safe and effective artificial blood product is currently marketed [6]. Here, it should be clarified that the term "artificial blood" is really a misnomer. The complexity of blood is far too great to allow for absolute duplication in a laboratory [7]. Hence, scientists are looking for alternative source of human blood i.e. placental blood, which could be saved and 
utilized. After birth, placenta is normally discarded but placental cord blood, because of its rich mix of fetal and adult hemoglobin, plasma, and high platelet count has the potential to be a safe alternative to adult blood [8]. The blood remaining in the placenta and cord is called placental blood or umbilical cord blood: "cord blood" for short. Along with all the normal elements of blood, cord blood is a rich source of hematopoietic (blood-forming) stem cells, similar to those found in bone marrow [9]. Placenta has $80 \mathrm{ml}$ to $150 \mathrm{ml}$ precious whole human blood that can be saved, stored and used as replacement of adult whole human blood [10]. Cord blood also has the potential, due to its rich cytokine and growth factor content to play a role in immune response modification in chronic anaemia [11] and also helps in the gene-switching mechanism after the birth of the baby [12]. Cord blood has a much higher hemoglobin, platelet and leukocyte content than adult whole blood. Present study is aimed to establish the fact that whole Umbilical cord blood is safe for transfusion and a true alternative to whole adult human blood as well as to access its usefulness in different clinical conditions i.e. autoimmune, degenerative, congenital, geriatric, malignancy etc.

\section{Materials and Methods}

The present prospective cross-sectional study was carried out from $1^{\text {st }}$ February 2015 to $31^{\text {st }}$ August 2016 at a tertiary care centre in Central India. A total of 150 umbilical cord whole blood units were collected and out of which, 120 fit units were transfused to 77 patients. Our patients were clinically grouped into transfusion dependent (i.e. Anaemia, Aplastic anaemia, and Thalassemia), degenerative disorders, hematopoietic malignancies and geriatric disorders. Umbilical Cord was collected in the Labor Room, Obstetrics and Gynecology Department, of our institute. All necessary pre-testing was done in blood bank and fit cord blood units were transfused to the pre-registered patients, referred by clinicians for cord blood transfusion. Prior to collection and transfusion of cord blood, informed written consent was taken from donor (mother) and the patient separately.

Cord blood was collected from healthy placenta and cord of normal vaginal deliveries in $100 \mathrm{ml}$ citrate phosphate dextrose (CPD; an anti-coagulant and preservative) bag via venipuncture of umbilical vein of cord. In whole procedure, aseptic precautions were on priority. Soon after delivery of baby, placenta was delivered out and kept in a sterile tray. Distal end of Cord was swabbed with betadine and cleaned with spirit swab, then the assistant was asked to hold the cord between two hands and umbilical vein was pierced by a needle connecting to bag. 80 to $120 \mathrm{ml}$ of placental cord blood was collected in bag through gravity. If collected blood $<60 \mathrm{ml}$ then unit was discarded. Soon after collection, blood unit was transported to blood bank in transportation container. If there was a delay, the units were kept in labor room refrigerator but delay was not more than 12 hours.

In Blood Bank, unit number for cord blood was given and $02 \mathrm{ml}$ blood was collected in test tube for blood bank procedures. Till all test procedures were carried out, unit was kept at $04^{0}-06^{0} \mathrm{C}$ in blood bank refrigerator. Complete (Forward and reverse) $\mathrm{ABO}$ and $\mathrm{RhD}$ grouping of unit along with detection of irregular antibodies of mother's origin (Direct Coombs test; DCT \& Indirect Coombs test; ICT) was done by Neonatal grouping Gel Card and Anti Human Globulin card (A coloumn agglutination method) Make - Tulip Diagnostic respectively.

Tests for transfusion transmitted infections (TTIs) of units i.e. Human Immuno- deficiency Virus (HIV), Hepatitis C (HCV) and Hepatitis B (HbsAg) was done by Enzyme Linked Immuno-sorbent Assay (ELISA) method using tests kit Make-Tulip and using ELISA reader make-Robonik while for Syphilis and Malaria rapid card test of make-Tulip were used. After complete blood grouping of the patient and its cross matching with the cord blood unit, compatible cord blood was transfused to pre-registered patients. Cord blood was transfused in clinical ward of hospitals. Any adverse event of transfusion; immediate or delayed were noted and follow up of the patents up to three months or more was done to observe the outcome of cord blood transfusion. All data was collected, compiled and compared statistically by frequency distribution and percentage proportion. Chi-square $(\chi 2)$ test was applied to know the statistically significant difference $(p$ value) of the data. Epicalc version 2000 software was used for the same. The data was also compared with similar studies from India and abroad.

\section{Results}

A total number of 150 cord blood units were collected from the healthy placenta of normal deliveries. Out of 150 cord blood units, 120 units were found to be fit for transfusion and remaining 30 units were unfit for transfusion ( $p<0.0001)$. Out of 30 units, 10 were rejected because of less quantity of blood collected $(<60 \mathrm{ml})$, 19 were rejected on immunological criteria and 01 was positive for TTIs, results were statistically significant $(p$ $<0.00034$ ) (Flow chart No.1 ). 
Flow Chart No.1: Utilized / Un-utilized cord blood units in the study

\section{Utilized and unutilized cord blood units}

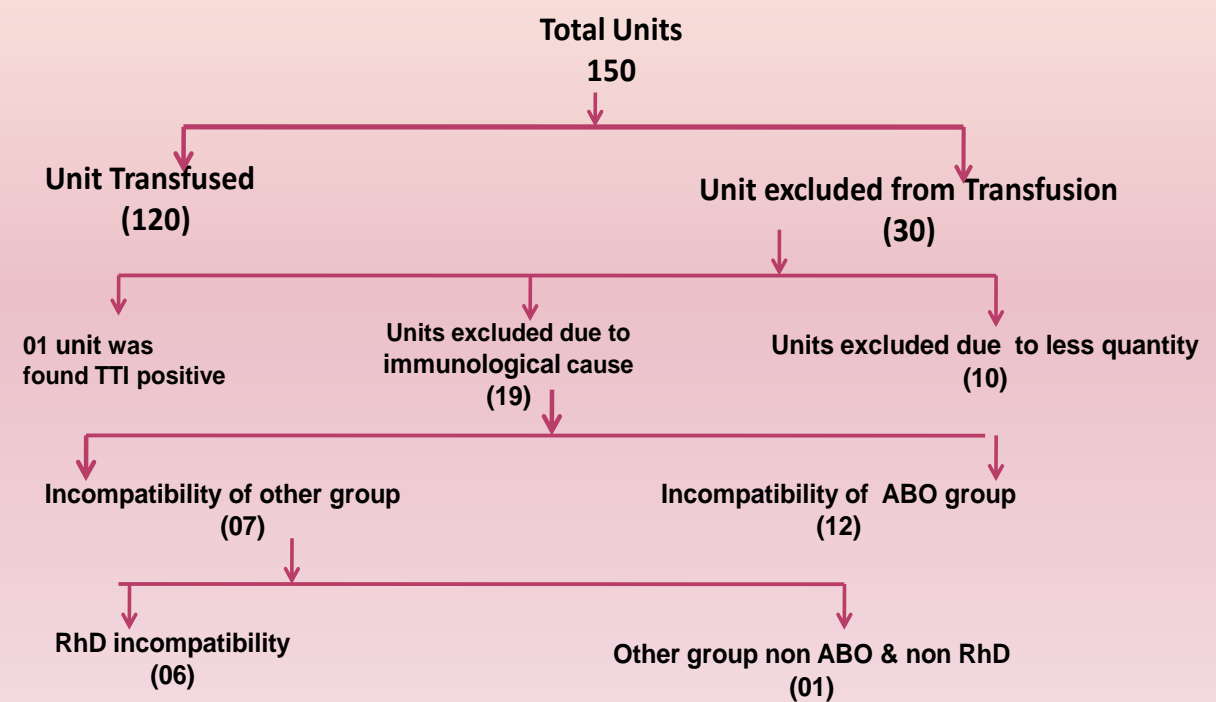

Blood volume per unit varied from 60 to $120 \mathrm{ml}$ with the mean of $80.75 \pm 13.06 \mathrm{SD}$. Age of the patients was from $<1$ year to 75 year. The average age of the patient was $26.19 \pm 20.5$ SD. 120 units of whole cord blood were transfused in 77 patients with the average of 1.5 unit/ Patient; minimum one and maximum 5 transfusions.

Out of 77 Patients, Males were $46(59 \%)$ and Females were $31(41 \%)$. ABO group distribution of the patients was - A: 20, B: 34, O: 16 and AB: 7 which is statistically significant $(p=0.00019)$. Two Patients were $\mathrm{Rh}-\mathrm{D}$ Negative and rest were Rh-D positive; statistically significant $(p=0.000001)$.

Number of Cord blood Transfusions in different clinical conditions was summarized in Figure no. 1

Figure No 1: Cord blood transfusion in different clinical conditions.

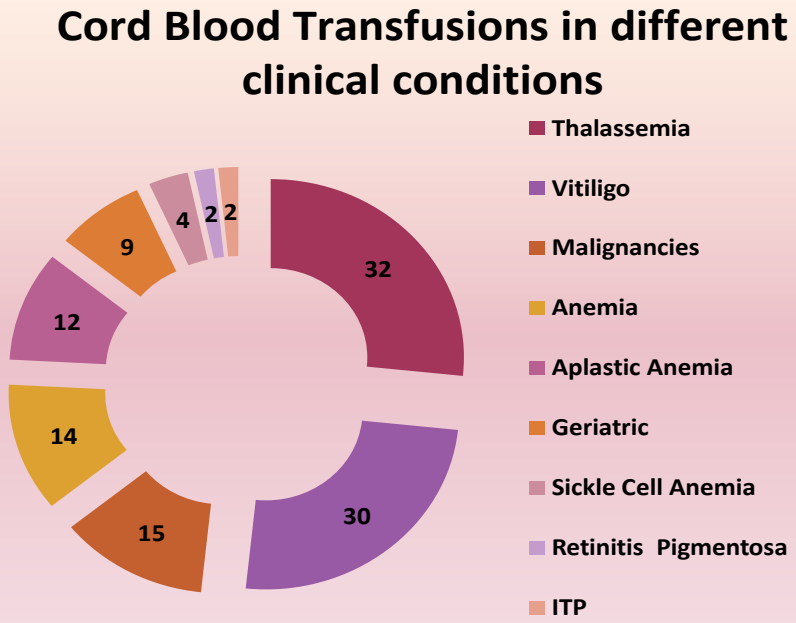


After transfusion of cord blood follow up of the patients was done up to 3 months and following observations were drawn. In different types of anemia i.e. thalassemia, neonatal anemia, aplastic anemia, sickle cell anemia, hematopoietic malignancy, hemoglobin level was increased by 0.5 to $1 \mathrm{gm} / \mathrm{dl}$ after 24 hours of cord blood transfusion, requirement of RBCs volume reduced by $10-20 \%$ and interval between two transfusions increased by $10 \pm 2$ days. In Idiopathic Thrombocytopenic patients cord blood transfusion resulted in stability of platelet counts at around 20-25000/mm3 and no bleeding episodes was noted with this count in our patients during follow up. In a case of retinitis Pigmentosa, 75 years old male with associated diabetes and asthma, two transfusions of whole cord blood with an interval of one month resulted in improvement in his vision field (Figure no. 2, 3) and patient was able to do indoor as well as outdoor activities independently even when daylight was dim. His diabetes was remarkably controlled and the patient also got rid of anti-asthmatic drugs after the transfusions.

\section{Field of vision}

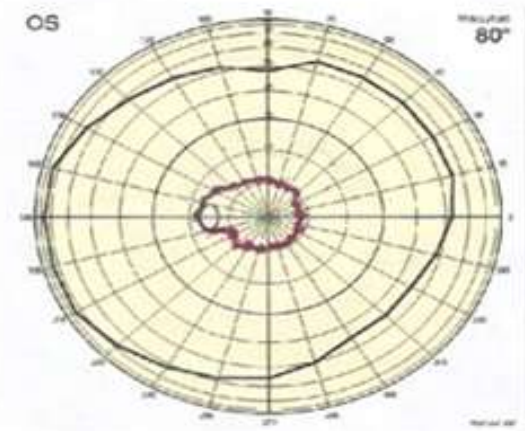

Left eye

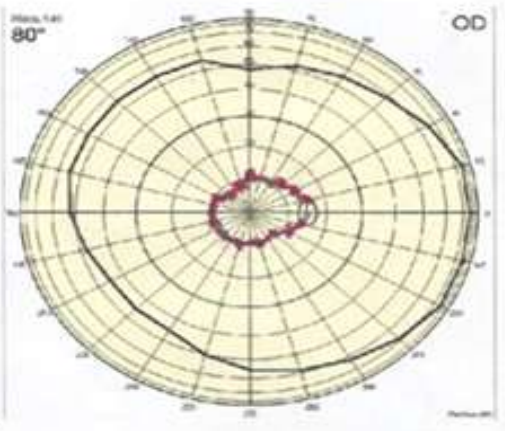

Right eye

Figure No. 2: Perimetry chart: field of vision (normal vision marked by black line and patient's vision marked by red line) before cord blood transfusion was at around $10-15^{\circ}$ fixation point (03-03-2016) Field of vision

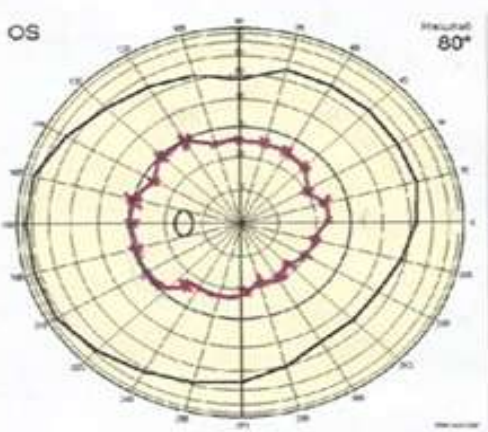

Left eye

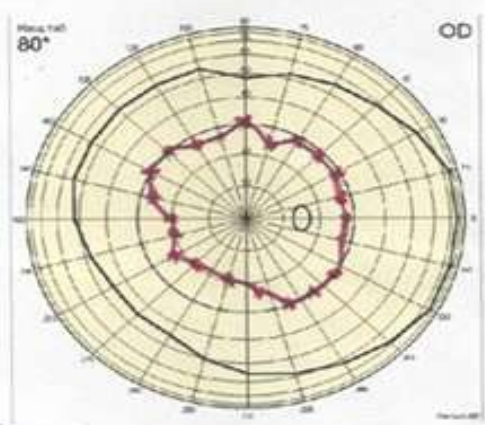

Right eye

Figure No. 3: Field of vision (normal vision marked by black line and patient's vision marked by red line) improved around $30^{\circ}$ fixation point after cord blood transfusion (dated 15-05-2016).

In 30 cases of vitiligo in which cord blood was transfused, subjects were chronic patients (Disease ranging from Months to almost 20 years). A good response $\left(2 / 3^{\text {rd }}\right.$ re-pigmentation in the affected area) was observed in $30 \%$ patients, average response (half re-pigmentation) was seen in $40 \%$ patients, poor response (minimal re-pigmentation) was seen in $20 \%$ patients whereas $10 \%$ of the patients didn't show any response. Cord Blood Transfusions were beneficial in the initiation of re-pigmentation in old, chronic, non-responding patients (Figure no, 4). 


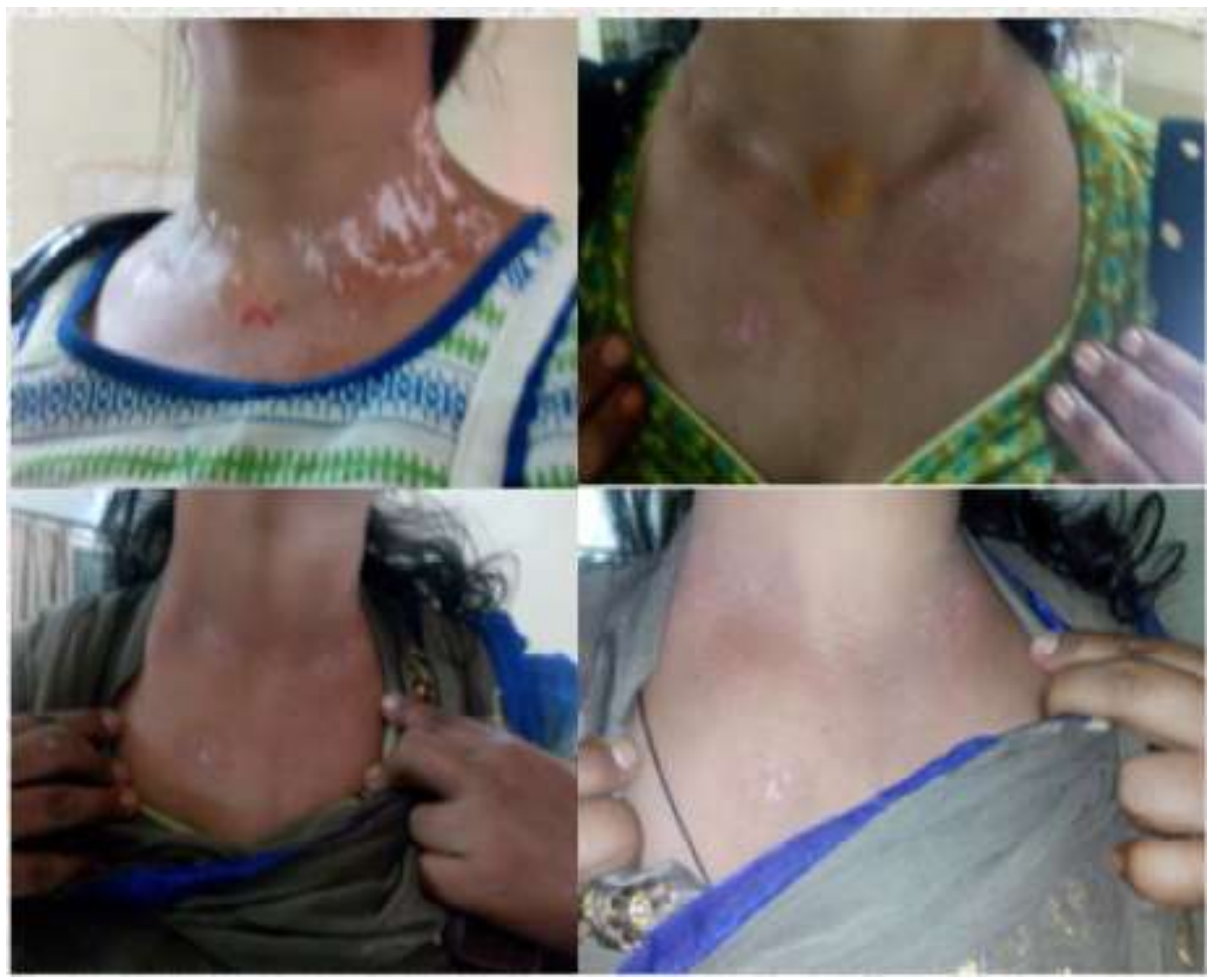

Figure no 4: A 28 year old girl recovered from vitiligo after cord blood transfusion and PRP treatment. (front of neck and chest)

Along with the primary disease, three of our patients had associated diabetes and after cord blood transfusion, their dose of anti diabetic drugs was reduced. In 7 geriatric patients who were having multiple complaints, after cord blood transfusion their symptoms were relieved and had feeling of general well being. In Newborns and neonates where the lesser quantity of blood was required, cord blood is better to adult blood for transfusion because there is privilege of growth factors and cytokines present in cord blood. Clinical outcome of cord blood transfusion in the present study was recapped in table no.1.

Table No. 1. Clinical outcome of cord blood transfusion in the present study

\begin{tabular}{|c|c|c|c|c|}
\hline $\begin{array}{c}\mathbf{S . N} \\
\mathbf{0}\end{array}$ & Clinical group & Diagnosis & $\begin{array}{c}\text { No. of } \\
\text { Transfusions }\end{array}$ & Clinical Outcome \\
\hline 1 & \multirow[t]{5}{*}{$\begin{array}{l}\text { Hematological } \\
\text { disorders }\end{array}$} & Thalassemia & 32 & $\begin{array}{c}\text { Improvement in hemoglobin \& Reduction } \\
\text { in frequency of Transfusion }\end{array}$ \\
\hline 2 & & Aplastic Anemia & 12 & $\begin{array}{l}\text { Improvement in hemoglobin Reduction in } \\
\text { frequency of Transfusion }\end{array}$ \\
\hline 3 & & Anemia & 14 & Improvement in hemoglobin \\
\hline 4 & & Sickle cell anemia & 04 & $\begin{array}{l}\text { Improvement in hemoglobin \& Reduction } \\
\text { in frequency of Transfusion }\end{array}$ \\
\hline 5 & & ITP & 02 & Stability of Platelet counts \\
\hline 6 & \multirow{2}{*}{$\begin{array}{l}\text { Degenerative } \\
\text { disorders }\end{array}$} & Vitiligo & 30 & Re-pigmentation in affected area \\
\hline 7 & & Retinitis Pigmentosa & 02 & Improvement in vision area \\
\hline 8 & Malignancies & $\begin{array}{c}\text { Hematological } \\
\text { malignancies }\end{array}$ & 15 & $\begin{array}{c}\text { Improvement in hemoglobin Stabilization } \\
\text { of disease process }\end{array}$ \\
\hline 9 & $\begin{array}{l}\text { Geriatric } \\
\text { Disorders }\end{array}$ & Geriatric Disorders & 09 & Improvement in geriatric problems \\
\hline \multicolumn{5}{|c|}{$\begin{array}{l}\text { Note: } \\
\text { (a) Three patients having associated diabetes had their blood sugar under control. } \\
\text { (b) One patient with Asthma got rid of his asthmatic symptoms. }\end{array}$} \\
\hline
\end{tabular}

Out of 120 cord blood transfusions, adverse events were reported only in $02(1.6 \%)$ cases; one patient had Febrile Non Hemolytic Transfusion Reaction (FNHTR) which might be due to platelet/ or leukocyte content of cord blood and one had allergic reaction in the form of itching over whole body which might be due to plasma proteins of cord blood. No case of other Immediate/delayed, immunological/ non-immunological including GvHD (Graft Versus Host Disease) and infective reactions was reported in the study. 


\section{Discussion}

In the present study, 120 units of cord Blood transfusions were given to 77 patients safely without encountering any immunological, non immunological and infective complication except routine adverse event of blood transfusion in 2 (1.6\%) transfusions, where we observed FNHTR and allergic reaction (one each). Similarly, in the year 2001 Bhattacharya $\mathrm{N}$ et al [10], has given 174 transfusion of cord blood in 62 patients in the cases of malignancies, in 2005 again Bhattacharya $\mathrm{N}$ et al [13] transfused 413 unit of whole cord blood to 129 patients of malignancies and other diseases and further in 2006 Bhattacharya N [14] transfused cord blood in 72 patients suffering with anemia and emaciation in the background of cancer safely. Lockwood DNG et al [15] transfused 44 units of umbilical cord whole blood in 12 patients of leprosy with anemia safely. Our study further strengthens the concept that umbilical whole cord blood is safe for transfusion and genuine alternative to whole human adult blood.

In the present study, volume of the cord blood ranged between $60 \mathrm{ml}$ to $120 \mathrm{ml}$ with the mean volume of $81 \mathrm{ml} \pm 12 \mathrm{SD}$. While, in the study of Bhattacharya $\mathrm{N}$ [16], it was $56 \mathrm{ml}$ to $132 \mathrm{ml}$ with mean of $82 \mathrm{ml} \pm 16 \mathrm{ml}$ SD and in study conducted by Lockwood DNG et al [15] volume of umbilical whole cord blood was 56-136 ml mean $81 \mathrm{ml} \pm 12 \mathrm{ml} \mathrm{SD}$ which is alike with our study. In our study, hematological findings were; hemoglobin of cord blood varied from 16.2 to $20.2 \mathrm{gm} \%$ (against the average adult hemoglobin $14.4 \mathrm{gm} \%$ ) with the average $72 \%$ of fetal hemoglobin. Average platelets and WBC count were 6,50,000/cumm and 20,000/cumm respectively which are comparable with the studies of Bhattacharya $\mathrm{N}$ in the Indian scenario while higher values was reported by Surbek DV et al [17] in his study on Human umbilical cord whole blood, Hemoglobin (20 gm\% against $14.4 \mathrm{gm} \%$ of adult hemoglobin, with 70 percent fetal Hemoglobin), platelet concentration of $7,50,000$ against 2,50,000/ $\mu 1$ of adult blood and a WBC count of cord blood 24,000 against 6500-10,500 cells/ $\mu \mathrm{l}$ in adult blood. In present study, age of patients ranges from less than 1 year to more than 60 years, while in study done by Bhattacharya et al 2006 [16] on the patients of malaria with anemia, it was 8 to 72 years and it was 48 to 74 years for diabetes with anemia patients by same author[18].

Allogenic cord blood transfusion was first reported in the 1930s. Before the advent of modern blood transfusion services, most researchers and clinical activities relating to cord blood transfusion have concerned autologous cord blood transfusion in preterm neonates. In India, a series of about 200 mainly elderly patients with chronic and terminal disease has received allogenic cord blood transfusion safely [19]. In the present study, allogenic cord blood was transfused in patients with varying diseases. Bhattacharya $\mathrm{N}$. et al $[10,13]$ did such type of study while in other studies; researchers had worked on a selective group of patients [15, 20]. A total number of 32 transfusions were given in Thalassemic patients. We have taken blood samples of patients before and 24 hours after transfusion. The hemoglobin level increased from 0.5 to $1.0 \mathrm{gm} / \mathrm{dl}$ in $70-80 \%$ of patients. Hemoglobin estimation was repeated after a week where there was marked secondary rise in the hemoglobin concentration which may be due to cytokine stimulation effect of cord blood on the host bone marrow similarly reported by Bhattacharya $\mathrm{N}$ [21]. Due to higher $\mathrm{O}_{2}$ carrying capacity of fetal hemoglobin lesser quantity of $\mathrm{RBCs}$ were required which is helpful in reducing iron overload and preventing heart failure in these chronic transfusion dependent patients.

Cord blood is a rich source of cytokines and growth factors which are poorly present in adult blood [22]. We transfused cord blood in various degenerative diseases such as aplastic anemia, vitiligo, retinitis pigmentosa, and other geriatric diseases and the results were encouraging. Stems cells in cord blood are $0.01 \%$ of cellular population which is 10 times greater than the adult peripheral blood $(0.001 \%)$ while it was $0.1 \%$ in bone marrow [23]. Stem cell therapy along with growth factors and cytokines can be provided to the patients simply by cord blood transfusion which is helpful in various clinical conditions. Mismatched adult stem cells are rejected immunologically by the host but cord blood stem cells which are hypo-immunogenic and immunologically innocent, can be accepted by natural matching. The use of cord blood stem cells in treating conditions such as brain injury[24] and type 1 diabetes [25] is already being studied in humans and earlier stage research is being conducted for treatment of stroke[26, 27] and hearing loss [28]. Experimental studies are going on animal models that cord blood stem cells injected intravenously have the ability to migrate to the area of brain injury, alleviating mobility related symptoms [29, 30]. In the 06 cases of Aplastic anemia where we have given 12 transfusions of cord blood in the present study, regeneration of bone marrow/transplant of cord blood stem cells was not observed. Though improvement in general condition was observed which may be due of fetal hemoglobin of RBCs, cytokines and growth factors of cord blood and our one patient is still with us and surviving till date with minimum dependence of RBCs and platelets. In the present study, two cord blood transfusions were given in a patient of retinitis pigmentosa within the interval of one month. Patient's vision area was improved (Figure no. 2 \& 3). He was visionless since last five years, was not reported in any other related studies. More work in this field can be helpful to conclude any observation because in present study there was only one case.

In the study, we have given 30 cord blood transfusions to vitiligo patients. Our patients were new patients with 6 months history to chronic patients with 20 years history of vitiligo. Our results were encouraging 
which is illustrated in the Figure no.4. To best of our knowledge no such type of observation was reported previously. In our study we have transfused 15 cord blood units to 4 patients with hematopoietic malignancy. No cases of other malignancies were included in present study. In a similar study done by Bhattacharya N. 2006 [20] multiple number of transfusions were given to six malignant cases and he reported change in CD34 level in peripheral blood. One of their cases showed a frequent steep rise up to 99\% and a sustained high level of CD34 with clinical remission of disease. We observed only general improvement in leukemic patients. We did not study for CD34 level in peripheral blood. In present study we have given 09 transfusions in neonatal anemia. There may be therapeutic benefit of reducing transfusion transmitted infections and easy availability. In a study done by A. Ballin et al [31] umbilical cord blood transfused in neonates and they stated that the fetal blood left in the placental vessels may serve as a source of blood for auto-transfusion. Umbilical cord blood, enriched with self hematopoietic growth factors and progenitor cells, may be beneficial to premature infants who frequently suffer from leucopenia and thrombocytopenia caused by lack of marrow reserve. It shows that cord blood can be transfused safely as autologous as well as allogenic transfusion in neonates.

In the present study, ABO matched HLA randomized 120 units of cord blood were given to 77 individuals without encountering any clinical features of graft versus host disease (GvHD). The basic fact appears to be that the homeostatic proliferation in lymphopenic environment actually causes GvHD following ablation of host $\mathrm{T}$ cells. This creation of an empty compartment allows for homeostatic expansion of the newly introduced $\mathrm{T}$ cells, which primes them for aggressive immune reactions and alleviates their requirement for co stimulation [32]. GvHD is not an intrinsic property of the allogenic cells introduced into host but a result of lymphoablation induced in the recipient prior to cellular administration [33]. For GvHD two conditions; Immuno-compromised patients and partially matched HLA i.e. transfusion between first degree relative is decisive and none of the above mentioned conditions applied to our patients. Therefore there is a least possibility of GvHD and we did not come across any case of GvHD. Out of 120 units of cord blood transfusions, only in $02(1.6 \%)$ transfusions adverse event of routine blood transfusion; one each of FNHTR and allergic reaction was reported and managed symptomatically. None other author included the adverse event of transfusions and number of unfits units in their study.

\section{Conclusion}

From our observations we concluded that umbilical cord whole blood is a whole human blood and a genuine alternative of adult human blood in routine and emergencies. It is useful in neonates and helpful in correction of anemia in transfusion dependent patients of any age group. From our study we also observed that it is a hope for geriatric, autoimmune and degenerative diseases. So with our preliminary study, we concluded that this precious human resource can be preserved and utilized in the goodness of patients and more extensive work is to be done to explore the possibility of future.

\section{Acknowledgment}

The author(s) are thankful whole-heartedly to Dr. S. N. Iyenger Head of the Institute, Dean G.R. Medical College and Dr. J. S. Sikarwar Superintendent and Joint Director, J. A. Group of Hospital, Gwalior for their close cooperation and unstinted support without which this study would have not been possible. The author(s) are also thankful to Mrs. Seema Pathak, and Mr. Dharmendra, technicians' blood bank, J. A. Hospital, Gwalior for their cooperation in the study.

\section{Ethical Approval}

All author(s) hereby declare that all procedure (collection of umbilical cord blood and its transfusion in preregistered patients ) have been examined and approved by the appropriate ethics committee of Gajra Raja Medical College, Gwalior and appraisal committee of state government of Madhya Pradesh, India. Research has therefore been performed in accordance with the ethical standards laid down in the 1964 declaration of Helsinki.

\section{Patient's and Donor's consent}

Informed written consent has been taken from the patient in whom cord blood has been transfused as well from donor (mother) from cord blood has been procured for the study.

\section{Funding}

This research did not utilize any specific grant from any funding agency in the public, commercial or nonprofit organizations.

\section{Competing Interests}

Authors have declared that there are no competing interests. 


\section{References}

[1]. Pal R., Kar S., Zaman F. A. \& Pal. S. (2011). The quest for an Indian blood law as of blood transfusion services regulatory framework. Asian J Transfus Sci, 5(2), 171-174. doi: 10.4103/0973-6247.83246.

[2]. Agarwal, S. P. (2012). National Voluntary Blood Donation Day- Message of The Secretary General. from http://www.indianredcross.org/sg-message-27-sep-2013.htm

[3]. Aggarwal S. and Sharma V. (2012). Attitudes and problems related to voluntary blood donation in India: A short communication. Ann Trop Med Public Health, 5(50).

[4]. Available from: http://www.medindia.com/news/Shortage-of-Blood-in-India-as-Blood-Banks-Do-Not-Maintain-Buffer-Stocks37199-1.htm. [Last accessed on 2011 May 5].

[5]. Sarkar S. Artificial blood; Indian J Crit Care Med. 2008 Jul-Sep; 12(3): 140-144 doi: 10.4103/0972-5229.43685 PMCID: PMC2738310

[6]. Kresie L. Artificial blood: an update on current red cell and platelet substitutes. Proc (Bayl Univ Med Cent). 2001 Apr; 14(2): 158161. PMCID: PMC1291332.

[7]. Bhattacharya N. Placental umbilical cord whole blood transfusion: a safe and genuine blood substitute for patients of the underresourced world at emergency. J Am Coll Surg. 2005 Apr; 200(4):557-63.

[8]. What is cord blood? - National Cord Blood Program. Available at www.nationalcordbloodprogram.org/qa/

[9]. Bhattacharya N, Mukherjee KL, Chettri MK et al. A study report of 174 units of placental umbilical cord whole blood transfusion in 62 patients as a rich source of fetal hemoglobin supply in different indication of blood transfusion. Clip Exp Obst \& Gyn 2001; 28(1):47-52.

[10]. McCracken S, Layton JE, Shorter SC, Starkey PM, Barlow DH, Mardon HJ. Expression of granulocyte-colony stimulating factor and its receptor is regulated during the development of the human placenta. J Endocrinol. 1996;149:249-258. doi: 10.1677/joe.0.1490249.

[11]. Stubblefield PG. Frontiers of Cord Blood Science. www.stmkolkata.org/rmts/research/FrontiersOf CordBloodScience.pdf

[12]. Bhattacharya N. Placental umbilical cord whole blood transfusion: a safe and genuine blood substitute for patients of the underresourced world at emergency. J Am Coll Surg. 2005 Apr; 200(4):557-63.

[13]. Bhattacharya N, A study of placental umbilical cord whole blood transfusion in 72 patients with anemia and emaciation in the background of cancer. Eur J Gynaecol Oncol. 2006; 27(2):155-61.

[14]. Lockhood DNG and Kumar B. Treatment of leprosy: A preliminary Study report on Placental Umbilical cord blood transfusion in victims of anemia with Leprosy in Under resourced regions of the World. BMJ 2004; 328 doi: https://doi.org/10.1136/bmj. 328 7454.1447 (Published 17 June 2004) Cite this as: BMJ 2004; 328:1447

[15]. Bhattacharya N. A preliminary study of placental umbilical cord whole blood transfusion in under-resourced patients with malaria in the background of anemia. Published: 23 March 2006 Malaria Journal2006, 5:20

[16]. Surbek DV, Glanzmann R, Senn H-P, et al. Can cord blood be used for autologous transfusion in preterm neonates? Eur J Pediatr. 2000; 159:790-791.

[17]. Bhattacharya N, Placental umbilical cord blood transfusion: a new method of treatment of patients with diabetes and microalbuminuria in the background of anemia. (Clin Exp Obstet Gynecol. 2006; 33(3):164-8.

[18]. Hassall OW, Thitiri J, Fegan G, Hamid F, Mwarumba S, Denje D, Wambua K, Mandaliya K, Maitiand K. Safety and efficacy of allogenic umbilical cord red blood cell transfusion for children with severe anemia in a Kenyan hospital: an open-label single-arm trial. The Lancet. Mar 2015;2(3)e101-107.

[19]. Bhattacharya N. Spontaneous transient rise of CD34 cells in peripheral blood after 72 hours in patients suffering from advanced malignancy with anemia: effect and prognostic implications of treatment with placental umbilical cord whole blood transfusion. European journal of gynaecological oncology. 2005 Dec; 27(3):286-90.

[20]. Bhattacharya N. Study of the utility of placental cord blood in meeting the transfusion needs of beta-thalasseaemic patients. Regional health forum. 2008; 12(2):16-27.

[21]. Hata T, Kawamura T, Inada K, Fujiwaki R, Ariyuki Y, Hata K, Kitao M. Cord blood cytokines and soluble adhesion molecules in vaginal and cesarean delivered neonates. Gynecol Obstet Invest. 1996;42(2):102-4.

[22]. Proctor SJ, Dickinson AM, Parekh T, Chapman C. Umbilical cord blood banks in the UK. BMJ. 2001 Jul 14;323(7304):60-1.

[23]. Cotten CM et al. Cord Blood for Neonatal Hypoxic-Ischemic Encephalopathy, Autologous Cord Blood Cells for Hypoxic Ischemic Encephalopathy Study 1. Phase I Study of Feasibility and Safety. J Pediatr. 2014 May; 164(5):973-979.e1. doi: 10.1016/j.jpeds.2013.11.036. Epub 2013 Dec 31

[24]. Haller MJ; Viener, HL; Wasserfall, C; Brusko, T; Atkinson, MA; Schatz, DA. Autologous umbilical cord blood infusion for type 1 diabetes. Exp. Hematol. 2008;36 (6): 710-715.

[25]. Vendrame M, et al. Cord blood rescues stroke-induced changes in splenocyte phenotype and function. Exp. Neurol.2006; 199 (1): 191-200.

[26]. Vendrame M, et al. Anti-inflammatory effects of human cord blood cells in a rat model of stroke". Stem Cells Dev. 2005; 14(5): 595-604.

[27]. Revoltella RP, et al. Cochlear repair by transplantation of human cord blood CD133+ cells to nod-scid mice made deaf with kanamycin and noise. Cell Transplant. 2008;17(6): 665-678.

[28]. Lu D, et al. Intravenous administration of human umbilical cord blood reduces neurological deficit in the rat after traumatic brain injury. Cell Transplant. 2002;11(3): 275-281.

[29]. Meier, C.; Middelanis, Johannes; Wasielewski, Bianca; Neuhoff, Sandra; Roth-Haerer, Astrid; Gantert, Markus; Dinse, Hubert R.; Dermietzel, Rolf; Jensen, Arne. "Spastic paresis after perinatal brain damage in rats is reduced by human cord blood mononuclear cells". Pediatr. Res. 2006;59(2): 244-249.

[30]. Ballin A, Arbel E, Kenet G, Berar M, Kohelet D, Tanay A, Zakut H, Meytes D. Autologous umbilical cord blood transfusion. Arch Dis Child. 1995; 73: F181-F183.

[31]. Marleau AM, Sarretnick N. T cell homeostasis in tolerance and immunity. J Leukon Biol. 2005; 78:575-84.

[32]. Riordan NH, Chan K, Marlean AM, Ichim TE. Cord blood in regenerative medicine; do we need immune suppression! J Transl Med. 2007; 5:8. 